Disease control by micrograzers

\title{
1 Microbial grazers may aid in controlling infections caused by aquatic
}

\section{2 zoosporic fungi}

3 Hazel N. Farthing ${ }^{2},{ }^{+}$Jiamei Jiang ${ }^{1},{ }^{+}$Alexandra J. Henwood ${ }^{2}$, Andy Fenton ${ }^{2}$, Trent

4 Garner $^{3}$, David R. Daversa ${ }^{2,3}$ Matthew C. Fisher ${ }^{4}$, David J. S. Montagnes ${ }^{2 *}$

5

$6 \quad{ }^{1}$ Shanghai Universities Key Laboratory of Marine Animal Taxonomy and Evolution, Key Laboratory

7 of Exploration and Utilization of Aquatic Genetic Resources, National Demonstration Center for

8 Experimental Fisheries Science Education, Shanghai Ocean University, Shanghai 201306 China

$9 \quad{ }^{2}$ Institute of Integrative Biology, BioSciences Building, University of Liverpool, Liverpool L69 7ZB

10 UK

11 Institute of Zoology, Zoological Society of London, London, England, UK

$12 \quad{ }^{4}$ MRC Centre for Global Infectious Disease Analysis, Imperial College London

+ These co- first authors contributed equally to this work.

* Correspondence:

David Montagnes

dmontag@liv.ac.uk

Key words: Batrachochytrium dendrobatidis, ciliates, disease, fungi, microbial loop, 
Disease control by micrograzers

\section{Abstract}

23

Free-living eukaryotic microbes may reduce animal diseases. We evaluated the dynamics by which micrograzers (primarily protozoa) apply top-down control on the chytrid Batrachochytrium dendrobatidis $(B d)$ a devastating, panzootic pathogen of amphibians. Although micrograzers consumed zoospores $(\sim 3 \mu \mathrm{m})$, the dispersal stage of chytrids, not all species grew monoxenically on zoospores. However, the ubiquitous ciliate Tetrahymena pyriformis, which likely co-occurs with $B d$, grew at near its maximum rate $\left(r=1.7 \mathrm{~d}^{-1}\right)$. A functional response (ingestion vs. prey abundance) for T. pyriformis, measured using sporesurrogates (microspheres) revealed maximum ingestion $\left(I_{\max }\right)$ of $1.63 \times 10^{3}$ zoospores $^{-1}$, with a half saturation constant $(k)$ of $5.75 \times 10^{3}$ zoospores $\mathrm{ml}^{-1}$. Using these growth and grazing data we developed and assessed a population model that incorporated chytrid-host and micrograzer dynamics. Simulations using our data and realistic parameters obtained from the literature suggested that micrograzers could control $B d$ and potentially prevent chytridiomycosis (defined as $10^{4}$ sporangia host $^{-1}$ ). However, simulated inferior micrograzers $\left(0.7 \times I_{\max }\right.$ and $\left.1.5 \mathrm{x} k\right)$ did not prevent chytridiomycosis, although they ultimately reduced pathogen abundance to below levels resulting in disease. These findings indicate how micrograzer responses can be applied when modelling disease dynamics for $B d$ and other zoosporic fungi. 
Disease control by micrograzers

\section{Introduction}

Although the traditional microbial food web (i.e. prokaryotes and protists, sensu Azam et al. [1] is well-established as a driver of aquatic productivity [2], micro-fungi are only now being appreciated as integral aquatic microbes. A dominant group of micro-fungi, the chytrids, are parasites of phytoplankton, zooplankton, and vertebrates [3], and zoospores, the chytrid dispersal stage, are argued to be nutritious and of an appropriate size for protozoan grazers $[2,3]$. Hence, through top-down control micrograzers within the microbial food web have the potential to reduce the likelihood or severity of, or even prevent, disease outbreaks caused by these pathogens [3-5]. Here, by developing and parameterizing a population model we explore the dynamics by which microbial grazers may control the chytrid Batrachochytrium dendrobatidis, a panzootic pathogen of amphibians that is argued to have caused the greatest loss of biodiversity attributed to any disease [6].

Batrachochytrium dendrobatidis (henceforth, $B d$ ) infects amphibian hosts through the dispersal of motile, 3-5 $\mu \mathrm{m}$ zoospores (Fig. 1). The environmental pool of zoospores is instrumental in driving infection dynamics, as these can accrue in a dose-dependent manner [7], with for some hosts the size of the zoospore pool influencing long-term consequences for population survival or extinction [8]. It follows that processes that reduce the zoospore-pool should reduce the probability and intensity of disease outbreaks. Consumption of zoospores by naturally occurring micrograzers has been suggested to result in losses sufficient to reduce infections. Experiments show that some micrograzers may reduce the likelihood of $B d$ infections, and field data indicate a negative relationship between potential-grazer abundance and both the prevalence of infection and host mortality from disease [9-12]. There is now a need to build on these observations and investigate in more depth the dynamics by which consumers may impact on $B d$. 
Disease control by micrograzers

Most work to date on the consumption of $B d$ zoospores has focused on large zooplankton, especially cladocerans $[10,13-15]$. However, experiments on cladocerans have used unrealistically high micrograzer abundances ( $>10-100$ times higher than natural levels), and at natural levels large zooplankton seem to have little impact on $B d$ infections [16]. Micrograzers, in contrast, are abundant in shallow waters and are often near the bottom of ponds where infected hosts (e.g. benthic, grazing tadpoles) spend time resting and grazing on the substrate [17-19]. Furthermore, as many protozoa have generation times on the order of hours, by reproducing asexually when zoospores are abundant, micrograzer populations may increase several fold, consuming zoospores as they are released from the host. We, therefore, argue that protozoa will be more important than cladocerans in reducing the abundance of chytrid zoospores. This is supported by Schmeller et al. [12] who, using mesocosms, showed the ciliate Paramecium can significantly reduce the number of hosts infected with $B d$ by up to $65 \%$ when it is introduced at naturally occurring abundances.

We also suggest that the main impact of micrograzers on $B d$ spore-load will be in the water directly surrounding the host, where zoospores will be most abundant. Field studies suggest that in water bodies where $B d$ occurs, zoospore densities in the water column are low, ranging from $\sim 0.5$ to $500 \mathrm{~L}^{-1}[20,21]$. In contrast, zoospores are shed from hosts at up to 250 zoospores $\min ^{-1}$ [22], surviving only $\sim 1-3$ days [9]. Additionally, zoospores mostly disperse on the order of $1 \mathrm{~cm}$ [23], demonstrating chemotaxis towards keratinised skin over this distance $[24,25]$. Although these laboratory-based rates will be dependent on environmental factors such as temperature [9], they suggest that the limited movement and survival of the rapidly produced zoospores will lead to dense aggregations in localized regions around the host. Recognising the likelihood of these local abundances and the well-established densitydependent feeding and growth responses of micrograzers [2], in this study we focused attention on the impact of micrograzers on $B d$ dynamics around the host. We achieved this 
Disease control by micrograzers

by: first, investigating a range of potential micrograzers, determining which survived on a diet of only $B d$ zoospores, and concentrating on those that grew; second, measuring ingestion and growth rates of a common species that thrives on $B d$; and third, using these data, developing and exploring a model that couples the $B d$ life-cycle with micrograzer-control on zoospores. In doing so, we indicate the dynamics by which micrograzers may reduce $B d$ populations - potentially preventing disease - and provide a mechanism by which chytriddiseases can be incorporated into microbial food web models.

\section{Materials and methods}

\section{Culture maintenance}

Batrachochytrium dendrobatidis (Bd) cultures (strain \#262 IA 9'13, Imperial Collage London) were maintained at $18{ }^{\circ} \mathrm{C}$ (at which all experiments were conducted) on $\mathrm{H}$-broth medium (500 mL: $5 \mathrm{~g}$ Tryptone and $16 \mathrm{~g}$ glucose) and were regularly transferred (every $\sim 5 \mathrm{~d}$ ) to maintain exponential growth. Bacterial growth was prevented by the addition of antibiotics (Ampicillin at $100 \mu \mathrm{g} \mathrm{ml}^{-1}$; Kanamycin at $50 \mu \mathrm{g} \mathrm{ml}^{-1}$; Chloramphenicol at $34 \mu \mathrm{g}$ $\mathrm{ml}^{-1}$ ). Micrograzers were obtained from Sciento (Manchester, UK): the ciliates Blepharisma sp., Oxytrichia sp., Paramecium aurelia, Paramecium caudatum, Stentor coeruleus, Tetrahymena pyriformis, and Urocentrum turbo and the rotifers Brachionus calcyciflorous and Philodina sp. Tetrahymena pyriformis was maintained axenically for extended periods on H-broth. All other species were maintained prior to experiments on a natural assemblage of bacteria in Chalkley's medium enriched with cereal grains, as provided by Sciento [26]. Assessing growth of micrograzer species on $\mathrm{Bd}$ zoospores

We tested the hypothesis that $B d$ zoospores were of nutritional benefit to the micrograzer. To do so, we compared growth with zoospores to when no food was available. 
Disease control by micrograzers

114 We also compared growth on zoospores to maximal rate of growth of the micrograzers, obtained from literature estimates (Fig 2).

Prior to introducing micrograzers, $B d$ was isolated from its growth medium to ensure that the medium was not a source of nutrients for the micrograzers. To do so, a $B d$ suspension (in exponential phase) was centrifuged (50 $\mathrm{ml}$ tubes, $5000 \mathrm{rpm}, 6 \mathrm{~min})$, the supernatant removed, and the pellet resuspended in autoclaved Volvic ${ }^{\circledR}$ mineral water to a concentration $>1.50 \mathrm{x}$ $10^{5} \mathrm{ml}^{-1}$ (determined microscopically). Bacterial growth was prevented with antibiotics, as above.

To assess growth rate, we followed our previous methods [27]. Micrograzers (9 species) were passed 5 times through autoclaved Volvic ${ }^{\circledR}$ water to remove bacteria. Then 5 to 8 individuals, dependent on micrograzer size, were added to a $10 \mathrm{ml}$ well containing the $B d$ suspension. Parallel treatments containing only sterile Volvic ${ }^{\circledR}$ water were used to assess mortality rate in the absence of prey. All treatments (i.e. species incubations with or without $B d$ ) were replicated in triplicate (i.e. three $10 \mathrm{ml}$ wells). To assess growth rate $\left(r, \mathrm{~d}^{-1}\right)$, the number of gazers in each well was determined microscopically after 2 or 3 days (depending on the observed change in abundance). Then, new $B d$ suspensions were prepared (as above), and micrograzers were transferred to these, maintaining $B d$ abundance. If micrograzer numbers decreased (net death occurred) over the incubation, then all individuals were transferred, but if numbers increased (net growth occurred) then the initial number was transferred. This procedure was continued for 14 days or until all micrograzers had died. Cultures were routinely checked to ensure there was no bacterial contamination.

When numbers increased between transfers, growth rate $\left(r, \mathrm{~d}^{-1}\right)$ was determined over each incubation period, as $r=\ln \left(N_{\mathrm{t}} / N_{0}\right) / t$, where $N_{0}$ and $N_{\mathrm{t}}$ are the micrograzer abundance on growth rate across all transfers (up to $14 \mathrm{~d}$ ), the average of these was obtained. When 
Disease control by micrograzers

micrograzer numbers decreased between transfers, mortality rates $\left(-r, \mathrm{~d}^{-1}\right)$ were determined as slope of $\ln$ numbers over the entire incubation period. To assess if growth (or death) rate differed between treatments (i.e. with or without $B d)$ a two tailed t-test was conducted $(\alpha=$ $0.05)$.

\section{Quantifying the functional response of Tetrahymena grazing on Bd}

Our study focused on Tetrahymena pyriformis as: 1) it grew rapidly on $B d$ zoospores (see Results) and therefore clearly consumed and assimilated zoospores; 2) it is a model organism for which there are substantial data (see Discussion), and 3) it is common, globally, in habitats where $B d$ may occur (see Discussion). Prior to determining ingestion rate, $T$. pyriformis was acclimated with zoospores for $>10 \mathrm{~h}$. To do so, the ciliates were first removed from $\mathrm{H}$-broth by centrifugation ( $50 \mathrm{ml}$ tubes, $8000 \mathrm{rpm}, 8 \mathrm{~min}$ ) and then resuspended in $10 \mathrm{ml}$ of autoclaved Volvic ${ }^{\circledR}$ water. To obtain only zoospores, a centrifuged $B d$ culture (as above) was filtered through a $5 \mu \mathrm{m}$ Nitex ${ }^{\circledR}$ mesh. Zoospores were then added to the water containing ciliates, to a total volume of $20 \mathrm{ml}$ (resulting in $\sim 10^{6}$ zoospores $\mathrm{ml}^{-1}$ ), with antibiotics (as above). This acclimation had no negative effects on the ciliates: after 10 h, zoospore abundance had substantially decreased and ciliate abundance increased (indicating the ciliates were feeding and growing), the ciliates behaved similarly to when grown on H-broth (i.e. similar swimming pattern), and their cell size and shape were similar to when grown on H-broth.

To determine ingestion rate on spore-sized particles, $3 \mu \mathrm{m}$ fluorescent polymer microspheres (henceforth beads, Fluoro-Max ${ }^{\mathrm{TM}}$, Thermo Fisher Scientific, USA,) acted as a surrogate for $B d$ zoospores which are 3 - $5 \mu \mathrm{m}[28]$. Bead concentrations, $\sim 8 \times 10^{3} \mathrm{ml}^{-1}$ to $10^{6} \mathrm{ml}^{-1}$ (see Results), were prepared in autoclaved Volvic ${ }^{\circledR}$ water and vortexed prior to use, ensuring mono-dispersion. An aliquot $(0.5 \mathrm{ml})$ of the acclimated ciliate culture $(>30$ micrograzers) was added to $1 \mathrm{ml}$ of Volvic ${ }^{\circledR}$ water with beads, at various concentrations (with 
Disease control by micrograzers

more measurements at low abundances [29], see Results), and incubated for 5 or $10 \mathrm{~min}$, depending on the bead concentration (preliminary experiments deemed these to be appropriate incubation periods). Incubations were terminated by fixing cells with ethanol (final concertation $70 \%$ ). The average number of beads ingested per ciliate ( $>30$ cells) was determined via fluorescent microscopy and was subsequently used to determine ingestion rate $\left(I\right.$, prey $\left.\mathrm{d}^{-1}\right)$ at each prey concentration.

The relationship between ingestion rate and zoospore abundance $\left(Z \mathrm{ml}^{-1}\right)$, was determined by fitting a Type II functional response to the data: $I=I_{\max } * Z /(k+Z)$, where $I_{\max }$ $\left(Z \mathrm{~min}^{-1}\right)$ is the maximum ingestion rate and $k$ is the half saturation constant $\left(Z \mathrm{ml}^{-1}\right)$. The response was fit using the Marquardt-Levenberg algorithm (SigmaPlot, Systat, Germany); this algorithm is appropriate for describing such biological data sets [30].

\section{Modelling micrograzer impacts on Bd populations}

To assess the dynamics by which grazing pressure impacts on $B d$ infection populations we developed and applied the following model that couples a reduced version of the $B d$-load model [8] with the Rosenzweig-MacArthur predator-prey model [31]. Data for T. pyriformis were used to represent micrograzers (see the Discussion for a justification to focus on this species). Following logic outlined in the Introduction, the model describes the infection load on a single host and, as a proxy for the waters surrounding the host, only considers a volume of $10 \mathrm{ml}$ around that host, where zoospores and micrograzers reside. As a metric to predict chytridiomycosis, it assumes that a sporangia load of $10^{4}$ per host results in host mortality [8], with the recognition that this will vary between hosts and $B d$ strains $[32,33]$. It does not include reduction of spore numbers by emigration as zoospores are unlikely to disperse far before dying [23], and we assume through chemokinesis, micrograzers remain near their food source[34-36]. The model is described by the following equations, 
Disease control by micrograzers

189

190

191

192

193

194

195

196

197

198

199

200

201

202

203

204

205

206

207

208

209

210

211

$$
\frac{d S}{d t}=y v Z-\sigma S
$$

where for Eq. 1 and Eq. 2, $S$ is the number of sporangia $\mathrm{ml}^{-1}$ (note for per host measurements this value is multiplied by 10$) ; Z$ is the zoospore abundance $\left(\mathrm{ml}^{-1}\right) ; y$ is the per capita sporehost encounter rate; $v$ is the fractional likelihood of spore infection per encounter; $\sigma$ is the per capita sporangia mortality rate; $\eta$ is the per sporangia spore-release rate; and $\mu$ is the per capita spore mortality rate (see Table 1).

Then, Eq. 2 and Eq. 3 were coupled to include spore loss by micrograzers $(G)$, where grazing $(I)$ is dictated by the functional response (see Tetrahymena pyriformis ingestion, above); $e$ is the abundance-based conversion efficiency, determined assuming a biomassbased estimate of $e$ is $\sim 0.1$ [37] and biovolumes of Bd zoospores and T. pyriformis; and $d$ is the micrograzer per capita death rate. We assume here that $B d$ zoospores are not the only potential food source for the micrograzers, and so incorporate a minimum micrograzer abundance $(b)$ that implicitly assumes that in the absence of zoospores the micrograzer population is maintained by the presence of other potential food sources; hence we model potential increases in micrograzer abundance over and above this minimum, dependent on consumption of $B d$ zoospores. Estimates of $d$ and $b$ are based on our unpublished observations. Table 1 summarises the above parameters and the estimates used.

All model runs $(100 \mathrm{~d})$ were initiated with 10 sporangia host $^{-1}\left(1\right.$ sporangium ml$\left.^{-1}\right), 100$ zoospores $\mathrm{ml}^{-1}$, and 1 micrograzer $\mathrm{ml}^{-1}$ (again assumed to be the minimal population size, maintained by other resources in the environment). For $B d$, we applied parameter values that were within the range explored by Briggs et al. [8] (Table 1).

We first performed simulations to assess the ability of $T$. pyriformis to control $B d$. Then, we assessed the extent to which micrograzers that are inferior to T. pyriformis could control 
Disease control by micrograzers

$B d$, through exploration of micrograzer parameter space. Inferior micrograzers had reduced maximum ingestion rate (up to $0.5 \times I_{\max }$ of $T$. pyriformis) and increased half saturation constant (up to $2 \times k$ of $T$. pyriformis); see Fig. 4 for an indication of the range of these responses. To quantify the impact of micrograzers on $B d$, we examined the maximum abundance (over the 100 days) and the abundances at 50 and 100 days of $S, Z$, and $G$.

\section{Results}

\section{Assessing growth of micrograzer species on $\mathrm{Bd}$}

All of the micrograzers can be maintained in laboratory cultures, with maximum growth rates ranging from $\sim 0.4$ to $2 \mathrm{~d}^{-1}$ (Fig 2), and all died when maintained on water alone, indicating their relative mortality rates when starved (Fig. 2). When fed $B d$, micrograzers exhibited four distinct responses (Fig. 2): 1) for the ciliate Stentor coeruleus the death rate was significantly (and substantially) higher than in water alone; 2) for the ciliates Urocentrum turbo, Blepharisma sp., and Oxytrichia sp. and the rotifer Philodina sp. there was no significant difference between death rate with or without $B d$; 3) for the rotifer Brachionus calcyciflorous growth rate initially increased (i.e. after $48 \mathrm{~h}$ ) followed by death, and for the ciliates Paramecium aurelia and P. caudatum (Fig. 3) the growth rate was initially positive when $B d$ was present followed by a negative growth rate as time progressed - on average over the incubation $P$. aurelia exhibited negative growth while $P$. caudatum exhibited zero growth (Fig. 3); and 4) for the ciliate Tetrahymena pyriformis there was a sustained positive growth rate (Fig. 2), which was significantly higher than the negative growth rate on water alone; this growth rate of $\sim 1.7 \pm 0.23$ (SE) $\mathrm{d}^{-1}$ was equal to that when the ciliate was grown axenically on $\mathrm{H}$-broth (unpublished data) and near its maximum rate under any conditions.

\section{Quantifying the functional response of Tetrahymena grazing on Bd}


Disease control by micrograzers

As T. pyriformis grew on zoospores alone it was clear that this ciliate ingested $B d$ zoospores. Zoospores were also observed in T. pyriformis, in the food vacuoles of the ciliate, under $40 \mathrm{x}$ magnification. Ingestion rate followed a typical Type II (rectangular hyperbolic) functional response (Fig. 4, adjusted $R^{2}=0.82$ ), with $I_{\max }=1.63 \times 10^{3} \pm 98(\mathrm{SE})$ prey $\mathrm{d}^{-1}$ and $k=5.75 \times 10^{3} \pm 1.38 \times 10^{3}(\mathrm{SE})$ prey $\mathrm{ml}^{-1}$.

\section{Modelling micrograzer impacts on Bd populations}

Control of $B d$ occurred when parameters for the micrograzer (T. pyriformis) were included in the model (Fig. 5). In the absence of the micrograzer, sporangia per host reached lethal levels $\left(>10^{4}\right.$ host $\left.^{-1}[8]\right)$ by $\sim 55$ days (Fig. 5a). However, when micrograzers were included their population rose from 1 to $\sim 35 \mathrm{ml}^{-1}$, with the result that sporangia were limited to a maximum of $3 \times 10^{3}$ per host (i.e. based on the assumption that $10^{4}$ sporangia is a lethal limit, the host would survive), and $B d$ was virtually eradicated by 100 days (Fig. 5b).

We then assessed the ability of micrograzers that were inferior to T. pyriformis to control $B d$, through exploration of micrograzer parameter space: i.e. up to twice the half saturation (k) and half the maximum ingestion rate $\left(I_{\max }\right)$ of T. pyriformis (Fig. 4). Fig. 5c illustrates population dynamics when the most inferior micrograzer was included (highest halfsaturation constant and lowest maximum ingestion rate): the general pattern remained similar to that when $T$. pyriformis parameters were applied, with the micrograzers controlling $B d$ over $100 \mathrm{~d}$, but the abundance of zoospores, sporangia, and micrograzers were more than 10 times greater than the simulation including $T$. pyriformis, leading to predicted host death at $\sim 55$ days and a peak in abundance at $\sim 70$ days.

We then examined the pattern of the temporal dynamics across a wider range of parameter space (representing a range of predators-types) by reporting the maximum abundance and the abundances at 50 and 100 days of zoospores, sporangia, and micrograzers. Across all parameters explored, the micrograzer population provided top-down control of $B d$, 
Disease control by micrograzers

as over the entire range $B d$ was virtually eradicated by 100 days (Fig. $6 \mathrm{c}, \mathrm{f}$ ). However, the quantitative levels and rates of control varied considerably with micrograzer efficiency: with reduced $I_{\max }$ and increased $k$, zoospores and sporangia reached higher maximum abundances (Fig. 6a, d) and persisted longer (Fig. 6b,e), indicating a decrease in the control of $B d$. In particular, micrograzers with $<0.7 I_{\max }\left(\sim 10^{3}\right.$ prey $\left.\mathrm{d}^{-1}\right)$ and $>1.5 \times k\left(\sim 9 \times 10^{4} \mathrm{ml}^{-1}\right)$ were not capable of preventing sporangia per host exceeding lethal levels of $10^{4}$ per host (the yellowto-red region on Fig. 6 d). Decreased $I_{\max }$ and increased $k$ also led to increases in micrograzer abundance (Fig 6. g-i), in response to the increased spore levels available under these grazing regimes.

\section{Discussion}

Control of a wide range of diseases caused by zoosporic fungi may be achieved through consumption on aquatic, motile zoospores by micrograzers [3-5]. Here, we explore the dynamics by which micrograzers may play a pivotal role in controlling the devastating amphibian disease chytridiomycosis, caused by the micro-fungus Batrachochytrium dendrobatidis $(B d)$. Previously, it has been shown that several micrograzers may consume $B d$ zoospores [12]. We expand on this by first indicating that some protozoa can also grow on $B d$ zoospores for short periods, and that the ubiquitous ciliate Tetrahymena pyriformis grows at near maximal rates on zoospores alone for extended periods. Recognising that micrograzers will grow on $B d$, provides essential information for modelling population dynamics. We then provide an assessment of the functional response of $T$. pyriformis feeding on spore-sized prey, also required for establishing a population model. Finally, using our data and literature estimates, we develop and employ a novel model that couples the $B d$ life cycle with micrograzer-control on zoospores. This synthesis reveals the dynamics by which 
Disease control by micrograzers

micrograzers may supress $B d$ loads and argues that for theoretical predictions of $B d$-host interactions it will be useful to consider embedding these into the larger microbial food web.

\section{Micrograzer growth on $\mathrm{Bd}$}

Previous work has suggested that a large range of micrograzers will consume $B d$ zoospores and may reduce $B d$ viability[12]. We have extended this observation by assessing if $B d$ provides nutritional benefits, that support micrograzer growth. All of the micrograzers we examined could ingest $B d$, but they exhibited a range of growth-responses. For one ciliate, $S$. coeruleus, $B d$ appeared to be toxic (possibly explaining previous reports that $S$. coeruleus does not reduce $B d$ viability;[12]), while other species seemed to obtain no nutritional benefit (Fig. 2). However, several species benefited from ingesting $B d$. Both Paramecium aurelia and P. caudatum initially grew, although this was not sustained (Fig. 3), suggesting that while $B d$ is of some value, it may lack essential nutrients for these ciliates. In contrast, Tetrahymena pyriformis sustained positive growth, indicating that $B d$ can provide a complete diet for certain species. These observations are supported by previous work on ciliates: T. pyriformis and a closely related species, Colpidium striatum, also grow on yeast (Saccharomyces), while $P$. aurelia, and $P$. caudatum cannot, again possibly due to a lack of nutrients such as essential fatty acids and B-vitamins [38, 39].

Our analysis, therefore, suggest that not all micrograzers would be capable of or equally proficient at controlling $B d$. However, with additional prey sources to sustain the consumers, there may be selective feeding on $B d$. For instance, $T$. pyriformis differentiates between prey, leading to a more efficient assimilation of prey biomass and a greater cell yield of ciliates [40]. Likely, in the mesocosm experiments conducted by Schmeller et al. [12], where Paramecium controlled $B d$, this ciliate's diet was supplemented by naturally occurring bacteria. In fact, in our initial growth-experiments, where antibiotics were not included, bacteria grew, and Paramecium caudatum consumed zoospores in addition to bacteria and 
Disease control by micrograzers

maintained extended positive growth (Supplement 1). Our analysis here has focused on $B d$ as the sole food source and indicates that micrograzer dynamics (growth and ingestion) lead to control of $B d$ populations. These findings argue that $B d$-host dynamics should now be examined in a wider food-web context, with mixed an assemblage of microgazers sustained by $B d$ and a wider range of natural food sources.

\section{Tetrahymena grazing on $\mathrm{Bd}$}

Globally, Tetrahymena is common in shallow waters, living near sediments, where it consumes bacteria and other microbes [41, 42]. These are the same habitats that $B d$ occupies. Tetrahymena is also associated with amphibians where it may be an opportunistic ectoparasite [43, 44], but possibly also a consumer of $B d$ zoospores as they emerge from sporangia. Considering its habitat and ability to rapidly reproduce on $B d$ alone, we focused on T. pyriformis' ingestion of $B d$ zoospores. In contradiction to Schmeller et al., attempts to stain $B d$ zoospores with calcofluor-white [12] were not successful; calcofluor stains chitin [45], and although $B d$ sporangia have a chitin wall, zoospores do not [28]. Therefore, this staining method seems inappropriate for $B d$ zoospores. We then explored vital stains (e.g. cell tracker green), but again we were not successful. Consequently, ingestion estimates relied on the uptake of fluorescent beads as surrogates for $B d$, which may underestimate rates (e.g. [46]). We, therefore, see our predictions as conservative. From our data, a clear Type II functional response was obtained for T. pyriformis (Fig. 4), providing essential parameters for modelling $B d$-micrograzer dynamics (see Methods). To our knowledge, this is the first time a functional response on $B d$ sized particles has been obtained for any Tetrahymena species: the estimates of $I_{\max }$ and $k$ are within the range of those obtained for other ciliates, although the $k$ values are on the lower end of the spectrum [39, 47, 48]; our modelling, therefore, includes micrograzers that are inferior to Tetrahymena.

\section{Modelling micrograzer impacts on Bd populations}


Disease control by micrograzers

Empirical evidence suggests that Paramecium can reduce $B d$ infections, through examining end point estimates of host infection [12]. Here we explore the temporal dynamics of such control and the potential for micrograzers to prevent host death. Our analysis is reductionist and hence more qualitative than quantitative in its predictions. However, it clearly reveals that by applying plausible parameters for both the parasite and micrograzer, in a local environment, chytridiomycosis may at times be prevented and $B d$ virtually eradicated, or at least reduced to negligible levels (Fig. 6). Critically, it suggests the time scales over which such dynamics may occur. Admittedly, we indicate that micrograzers that are inferior to T. pyriformis are less likely to prevent host death, yet they still, ultimately, reduce $B d$ populations to negligible numbers, potentially preventing further disease outbreaks (Fig, 6). Our model, therefore, provides a mechanism to evaluate $B d$-micrograzer dynamics, and its predictions strongly argue for the continued exploration of micrograzers in $B d$ research, specifically, and in the control of a range of diseases that spread through zoospores or other similarly sized dispersal stages [3-5].

To date, models of $B d$-dynamics $[8,9,49,50]$ have not included estimates of spore loss by micrograzers. As indicated above, the modelling provided here is instructive and could benefit from elaboration. Given the ubiquity of protozoa in natural waters [2], and the clear indication of their potential impact (Fig. 6, [3-5]), we suggest there is now a need for better parameterization of micrograzer- $B d$ responses. We suggest three main directions. First, micrograzers, and specifically Tetrahymena, exhibit chemosensory behaviour [35]; the extent to which protozoa are attracted to amphibian hosts and $B d$ requires evaluation. Second, as indicated above, the role of $B d$ as a supplement rather than a sole dietary component deserves attention. Finally, the Rosenzweig-MacArthur predator-prey model, which we used, has limitations. Model structures such as the independent response model [51] that rely, independently, on growth and ingestion responses provide better predictions [52]. To this 
Disease control by micrograzers

end, we suggest that both functional (ingestion) and numerical (growth) responses associated with $B d$ abundance are established for a range of micrograzers.

\section{Future directions for microbial ecology and $\mathrm{Bd}$}

Both Tetrahymena and Paramecium are common species in shallow waters [41, 42, 53], that, as we have shown, are capable of growth on $B d$ zoospores for limited to extended times. Undoubtedly, other protozoa will also consume and grow on $B d$ zoospores. We, therefore, suggest that the role of micrograzers is considered when evaluating $B d$-dynamics and the dynamics of other zoosporic diseases. Contributions of micrograzers to disease dynamics are also likely to have a highly site-specific component, due to their dependence on environmental factors [12]. For instance, chytridiomycosis is more prevalent at higher altitudes [34], which will often be both cooler and oligotrophic. While temperature may, in part, determine infection burdens [54], there will likely be an interaction with the trophic status of the water. If in oligotrophic waters bacteria are reduced below levels sufficient to support ciliates $\left(<10^{6} \mathrm{ml}^{-1}\right)$, top-down control may be absent, and our analysis suggests that $B d$ may thrive, resulting in chytridiomycosis. Consequently, assessing the abundance of micrograzers in waters where chytridiomycosis occurs or is predicted seems warranted.

We end with some speculations on the potential for biomanipulation using micrograzers, as this has been considered by others [12]. Traditional approaches for managing wildlife diseases have proven ineffectual or impractical for $B d$. Treating amphibians with probiotic bacteria directly has generally been unsuccessful as a conservation strategy (but see [34]), and, while theoretically plausible, culling hosts to below the critical threshold for disease transmission contravenes conservation objectives [55-57]. This means that alternative mitigation and management strategies must be perused. To date, the only successful effort towards in situ $B d$-mitigation relied on dosing animals with antifungal chemicals alongside applying chemical disinfectants directly to the environment to reduce spore survival [55]. 
Disease control by micrograzers

388 Fungicides and chemical disinfection, however, have shortcomings, not least of which are

389 ethical issues associated with indiscriminate toxic effects. As both Tetrahymena and

390 Paramecium are already common if not ubiquitous in aquatic environments and are simple

391 and inexpensive to grow in large quantities [42, 53], they may be tractable target species for

392 biomanipulation. We, therefore, support previous suggestions Schmeller et al. [12] that by

393 augmenting natural densities of these species, through addition or supplementary feeding, it

394 may be possible to reduce zoospore densities for $B d$ in situ. However, an introduction or

395 population increase of any species could have detrimental, ecosystem-changing effects that

396 require in depth evaluation before application [58]. Further evaluation of the role of

397 microgazers is, therefore, required before we can understand their likely impact in natural

398 conditions, and advocate the implementation of such approaches. 
Disease control by micrograzers

400

401 Acknowledgments

402 This work was conducted as part of postgraduate project (HF) at the University of Liverpool

403 and was supported by funding provided to JJ through the Program for Training University

404 Teachers by Shanghai Municipal Education Commission. AF and TG were funded by the

405 NERC grant NE/N009800/1. MCF is a CIFAR fellow with $B d$ research supported by NERC

406 NE/K014455/1. Eleanor Ambrose, Philip Bahan, Valentina Iorio, and Sam Moss provided

407 invaluable technical support.

408 Conflict of Interest

409 The authors declare that the research was conducted in the absence of any commercial or

410 financial relationships that could be construed as a potential conflict of interest. 
Disease control by micrograzers

412

413

414

415

416

417

418

419

420

421

\section{References}

1. Azam F, Fenchel T, Field JG, Gray JS, Meyer-Reil LA, Thingstad F. The ecological role of watercolumn microbes in the sea. Mar Ecol Prog Ser. 1983; 10: 257-63.

2. Fenchel T. Ecology of protozoa - the biology of free-living phagotrophic protists. New York, USA: Springer Verlag; 1987.

3. Kagami M, Miki T, Takimoto G. Mycoloop: chytrids in aquatic food webs. Front Microbiol. 2014; 5: 166.

4. Frenken T, Agha R, Schmeller DS, van West P, Wolinska J. Biological concepts for the control of aquatic zoosporic diseases. Trends Parasitol. 2019; 35: 571-82.

5. Grossart HP, Rojas-Jimenez K. Aquatic fungi: targeting the forgotten in microbial ecology. Curr Opin Microbiol. 2016; 31: 140-5.

6. Scheele BC, Pasmans F, Skerratt LF, Berger L, Martel A, Beukema W, et al. Amphibian fungal panzootic causes catastrophic and ongoing loss of biodiversity. Science. 2019; 363: 1459-63.

7. Garner TWJ, Walker S, Bosch J, Leech S, Marcus Rowcliffe J, Cunningham AA, et al. Life history tradeoffs influence mortality associated with the amphibian pathogen Batrachochytrium dendrobatidis. Oikos. 2009; 118: 783-91.

8. Briggs CJ, Knapp RA, Vredenburg VT. Enzootic and epizootic dynamics of the chytrid fungal pathogen of amphibians. Proc Natl Acad Sci U S A. 2010; 107: 9695-700.

9. Woodhams DC, Alford RA, Briggs CJ, Johnson M, Rollins-Smith LA. Life-history trade-offs influence disease in changing climates: strategies of an amphibian pathogen. Ecology. 2008; 89: 1627-39.

10. Buck JC, Truong L, Blaustein AR. Predation by zooplankton on Batrachochytrium dendrobatidis: biological control of the deadly amphibian chytrid fungus? Biodivers Conserv. 2011; 20: 3549-53.

11. Gleason FH, Lilje O, Marano AV, Sime-Ngando T, Sullivan BK, Kirchmair M, et al. Ecological functions of zoosporic hyperparasites. Front Microbiol. 2014; 5: 244. 
Disease control by micrograzers

12. Schmeller DS, Blooi M, Martel A, Garner TW, Fisher MC, Azemar F, et al. Microscopic aquatic predators strongly affect infection dynamics of a globally emerged pathogen. Curr Biol. 2014; 24: 176-80.

13. Hamilton PT, Richardson JML, Anholt BR. Daphnia in tadpole mesocosms: trophic links and interactions with Batrachochytrium dendrobatidis. Freshw Biol. 2012; 57: 676-83.

14. Maier MA, Uchii K, Peterson TD, Kagami M. Evaluation of daphnid grazing on microscopic zoosporic fungi by using comparative threshold cycle quantitative PCR. Appl Environ Microbiol. 2016; 82: 3868-74.

15. Searle CL, Mendelson JR, 3rd, Green LE, Duffy MA. Daphnia predation on the amphibian chytrid fungus and its impacts on disease risk in tadpoles. Ecol Evol. 2013; 3: 4129-38.

16. Buck JC, Rohr JR, Blaustein AR. Effects of nutrient supplementation on host-pathogen dynamics of the amphibian chytrid fungus: a community approach. Freshw Biol. 2016; 61: 110-20.

17. Dionne JC. Tadpole holes; a true biogenic sedimentary structure. J Sediment Res Sect B Stratigr Glob Stud. 1969; 39: 358-60.

18. Beiswenger RE. Diel patterns of aggregative behavior in tadpoles of Bufo americanus, in relation to light and temperature. Ecology. 1977; 58: 98-108.

19. Thurnheer S, Reyer HU. Diel patterns of aggregative behavior in tadpoles of Bufo americanus, in relation to light and temperature. Amphib-Reptilia. 2001; 22: 21-32.

20. Kirshtein JD, Anderson CW, Wood JS, Longcore JE, Voytek MA. Quantitative PCR detection of Batrachochytrium dendrobatidis DNA from sediments and water. Dis Aquat Organ. 2007; 77: 115.

21. Walker SF, Salas MB, Jenkins D, Garner TW, Cunningham AA, Hyatt AD, et al. Environmental detection of Batrachochytrium dendrobatidis in a temperate climate. Dis Aquat Organ. 2007; 77: $105-12$

22. Maguire C, DiRenzo GV, Tunstall TS, Muletz CR, Zamudio KR, Lips KR. Dead or alive? Viability of chytrid zoospores shed from live amphibian hosts. Dis Aquat Organ. 2016; 119: 17987. 
Disease control by micrograzers

23. Piotrowski JS, Annis SL, Longcore JE. Physiology of Batrachochytrium dendrobatidis, a chytrid pathogen of amphibians. Mycologia. 2004; 96: 9-15.

24. Moss AS, Reddy NS, Dortaj IM, San Francisco MJ. Chemotaxis of the amphibian pathogen Batrachochytrium dendrobatidis and its response to a variety of attractants. Mycologia. 2008; 100: $1-5$.

25. Garmyn A, Van Rooij P, Pasmans F, Hellebuyck T, Van Den Broeck W, Haesebrouck F, et al. Waterfowl: potential environmental reservoirs of the chytrid fungus Batrachochytrium dendrobatidis. PLoS ONE. 2012; 7: e35038.

26. Chalkley HW. Stock cultures of Ameba. Science. 1930; 71: 442.

27. Montagnes DJS. Growth responses of planktonic ciliates in the genera Strobilidium and Strombidium. Mar Ecol Prog Ser. 1996; 130: 241-54.

28. Berger L, Hyatt AD, Speare R, Longcore JE. Life cycle stages of the amphibian chytrid Batrachochytrium dendrobatidis. Dis Aquat Organ. 2005; 68: 51-63.

29. Montagnes DJS, Berges JA. Determining parameters of the numerical response. Microb Ecol. 2004; 48: 139-44.

30. Berges JA, Montagnes DJS, Hurd CL, Harrison PJ. Fitting ecological and physiological data to rectangular hyperbolae: a comparison of methods using monte carlo simulations. Mar Ecol Prog Ser. 1994; 114: 175-83.

31. Turchin P. Complex population dynamics: a theoretical/empirical synthesis. Oxford: Princeton University Press; 2003.

32. Kilpatrick AM, Briggs CJ, Daszak P. The ecology and impact of chytridiomycosis: an emerging disease of amphibians. Trends Ecol Evol. 2010; 25: 109-18.

33. Fisher MC, Bosch J, Yin Z, Stead DA, Walker J, Selway L, et al. Proteomic and phenotypic profiling of the amphibian pathogen Batrachochytrium dendrobatidis shows that genotype is linked to virulence. Mol Ecol. 2009; 18: 415-29.

34. Walker SF, Bosch J, Gomez V, Garner TW, Cunningham AA, Schmeller DS, et al. Factors driving pathogenicity vs. prevalence of amphibian panzootic chytridiomycosis in Iberia. Ecol Lett. $2010 ; 13: 372-82$. 
Disease control by micrograzers

35. Leick V, Hellung-Larsen P. Chemosensory behaviour of Tetrahymena. Bioessays. 1992; 14: 61-6.

36. Montagnes DJS, Barbosa AB, Boenigk J, Davidson K, Jürgens K, Macek M, et al. Selective feeding behaviour of key free-living protists. Aquat Microb Ecol. 2008; 53: 83-98.

37. Montagnes DJS, Zhu X, Gu L, Sun Y, Wang J, Horner R, et al. False exclusion: a case to embed predator performance in classical population models. Am Nat. 2019; 194: 654-70.

38. Hirayama K, Satuito C, The nutritional improvement of baker's yeast for the growth of the rotifer, Brachionus plicatilis, In: Fulks W, Main K, editors. Rotifer and microalgae culture systems. The Oceanic Institute, Honolulu: Proceedings of a U.S.-Asia Workshop; 1991. p. 151-62.

39. Pritchard JO, Porter AH, Montagnes DJS. Did gause have a yeast infection? J Eukaryot Microbiol. 2016; 63: 552-7.

40. Thurman J, Parry JD, Hill PJ, Laybourn-Parry J. The filter-feeding ciliates Colpidium striatum and Tetrahymena pyriformis display selective feeding behaviours in the presence of mixed, equally-sized, bacterial prey. Protist. 2010; 161: 577-88.

41. Doerder FP. Barcodes reveal 48 new species of Tetrahymena, Dexiostoma, and Glaucoma: phylogeny, ecology, and biogeography of new and established species. J Eukaryot Microbiol. 2019; 66: 182-208.

42. Simon EM, Nanney DL, Doerder FP, The Tetrahymena pyriformis complex of cryptic species, In: Foissner W, Hawksworth D, editors. Protist diversity and geographical distribution Dordrecht, the Netherlands: Springer; 2007. p. 131-46.

43. Holz PH, Portas T, Donahoe S, Crameri S, Rose K. Mortality in northern corroboree frog tadpoles (Pseudophryne pengilleyi) associated with Tetrahymena-like infection. Aust Vet J. 2015; 93: 2957.

44. Thompson JC. Experimental infections of various animals with strains of the genus Tetrahymena. J Eukaryot Microbiol. 1958; 5: 203-5.

45. Hageage GJ, Harrington BJ. Use of calcofluor white in clinical mycology. Laboratory Medicine. 1984; 15: 109-12.

46. Montagnes DJS, Lessard E. Population dynamics of the marine planktonic ciliate Strombidinopsis multiaris. Aquat Microb Ecol. 1999; 20: 167-81. 
Disease control by micrograzers

47. Gismervik I. Numerical and functional responses of choreo-and oligotrich planktonic ciliates. Aquat Microb Ecol. 2005; 40: 163-73.

48. Jürgens K, Šimek K. Functional response and particle size selection of Halteria cf. grandinella, a common freshwater oligotrichous ciliate. Aquat Microb Ecol. 2000; 22: 57-68.

49. Louca S, Lampo M, Doebeli M. Assessing host extinction risk following exposure to Batrachochytrium dendrobatidis. Proc Biol Sci. 2014; 281: 20132783.

50. Mitchell KM, Churcher TS, Garner TW, Fisher MC. Persistence of the emerging pathogen Batrachochytrium dendrobatidis outside the amphibian host greatly increases the probability of host extinction. Proc Biol Sci. 2008; 275: 329-34.

51. Fenton A, Spencer M, Montagnes DJS. Parameterising variable assimilation efficiency in predator-prey models. Oikos. 2010; 119: 1000-10.

52. Li J, Montagnes DJS. Restructuring fundamental predator-prey models by recognising preydependent conversion efficiency and mortality rates. Protist. 2015; 166: 211-23.

53. Görtz DH. Paramecium Berlin: Springer; 1988.

54. Cohen JM, McMahon TA, Ramsay C, Roznik EA, Sauer EL, Bessler S, et al. Impacts of thermal mismatches on chytrid fungus Batrachochytrium dendrobatidis prevalence are moderated by life stage, body size, elevation and latitude. Ecol Lett. 2019; 22: 817-25.

55. Bosch J, Sanchez-Tome E, Fernandez-Loras A, Oliver JA, Fisher MC, Garner TW. Successful elimination of a lethal wildlife infectious disease in nature. Biol Lett. 2015; 11: pii: 20150874.

56. Garner TW, Schmidt BR, Martel A, Pasmans F, Muths E, Cunningham AA, et al. Mitigating amphibian chytridiomycoses in nature. Philos Trans R Soc Lond B Biol Sci. 2016; 371: 20160207.

57. Hudson MA, Young RP, Lopez J, Martin L, Fenton C, McCrea R, et al. In-situ itraconazole treatment improves survival rate during an amphibian chytridiomycosis epidemic. Biol Conserv. 2016; 195: 37-45.

58. Symondson WOC, K. D. Sunderland, Greenstone MH. Can generalist predators be effective biocontrol agents? Annu Rev Entomol. 2002; 47: 561-94. 
Disease control by micrograzers

547 59. Kasturi Bai AR, Srihari K, Shadaksharaswamy M, Jyothy PS. The effects of temperature on Blepharisma intermedium. J Protozool. 1969; 16: 738-43.

60. Weithoff G, Walz N. Influence of the filamentous cyanobacterium Planktothrix agardhii on population growth and reproductive pattern of the rotifer Brachionus calyciflorus. Hydrobiologia. 1995; 313: 381-6.

61. Weisse T, Moser M, Scheffel U, Stadler P, Berendonk T, Weithoff G, et al. Systematics and species-specific response to $\mathrm{pH}$ of Oxytricha acidotolerans sp. nov. and Urosomoida sp. (ciliophora, hypotricha) from acid mining lakes. Eur J Protistol. 2013; 49: 255-71.

62. Finlay BJ. The dependence of reproductive rate on cell size and temperature in freshwater ciliated protozoa. Oecologia. 1977; 30: 75-81.

63. Salt JL, Bulit C, Zhang W, Qi H, Montagnes DJS. Spatial extinction or persistence: landscapetemperature interactions perturb predator-prey dynamics. Ecography. 2017; 40: 1177-86.

64. Inamori Y, Kuniyasu Y, Hayashi N, Ohtake H, Sudo R. Monoxenic and mixed cultures of the small metazoa Philodina erythrophthalma and Aeolosoma hemprichi isolated from a waste-water treatment process. Appl Microbiol Biotechnol. 1990; 34: 404-7.

65. Jackson KM, Berger J. Survival of ciliate protozoa under starvation conditions and at low bacterial levels. Microb Ecol. 1984; 10: 47-59.

66. Taylor WD. Maximum growth rate, size and commonness in a community of bactivorous ciliates. Oecologia. 1978; 36: 263-72.

67. Montagnes DJS, Kimmance S, Atkinson D. Using Q10: can growth rates increase linearly with temperature? Aquat Microb Ecol. 2003; 32: 307-13.

\section{Figure Legends}

569 Fig. $1 B d$ infectious life cycle including the potential grazing pressure by micrograzers.

570 Zoospores $(Z)$ move using a flagellum, and on contact infect the amphibian host. Within the host epidermal cells, a spore then forms a sporangium $(S)$ that releases further zoospores 
Disease control by micrograzers

572

573

574

575

576

577

578

579

580

581

582

583

584

585

586

587

588

589

590

591

592

593

through asexual reproduction $(n)$, after which the sporangium dies $(\sigma)$. Released zoospores may die naturally $(\mu)$ or be ingested $(I)$ by micrograzers $(G)$.

Fig. 2 Average growth rates $\left(r, \mathrm{~d}^{-1}\right)$ for micrograzers fed $B d$ (black) or no prey (grey); error bars are one standard error, and * indicates where significant $(\alpha=0.05)$ differences occurred between fed and unfed treatments. Note that for P. caudatum growth rate was zero when fed $B d$. The horizontal lines connected by a vertical line represent the range of predicted maximum growth rate (i.e. food saturated on suitable prey) at $18^{\circ} \mathrm{C}$, for each species. Data were obtained from a various sources at a range of temperatures [59-66] and were converted to rates at $18{ }^{\circ} \mathrm{C}$ by two methods, either assuming a $\mathrm{Q}_{10}$ of 2 or that growth rate varies linearly with temperature at a rate of $0.07 r\left(\mathrm{~d}^{-1}\right){ }^{\circ} \mathrm{C}^{-1}[67]$.

Fig. 3 Average growth rates $\left(r \mathrm{~d}^{-1}\right)$ of three replicates of Paramecium caudatum (a) and Paramecium aurelia (b) in the $B d$ treatment, with standard error bars. The skull and crossbones indicate the time point where all individuals had died. The solid black line represents the average death rate of the micrograzers when no prey were present, and the dotted black line indicates the standard error of the control groups.

Fig. 4 The functional response: ingestion rates of Tetrahymena pyriformis on surrogate zoospores (prey) vs prey concentration. Points are ingestion rates at defined prey abundances. The solid line represents the best fit of a Type II functional response to the data (see Results for the parameter estimates). The grey region represents the range of functional responses used to assess the ability of "inferior micrograzers" to control $B d$ (i.e. reduced maximum ingestion rate and increased half saturation constant; see Methods, Modelling micrograzer impacts on $B d$ populations). 
Disease control by micrograzers

594 Fig. 5 Simulations of micrograzer (T. pyriformis) control of $B d$, based on Eq. 1-3 and 595 parameters presented in Table 1. a. $B d$ (zoospore and sporangia) dynamics in the absence of 596 micrograzers, indicating that by $\sim 55$ days sporangia per host approach lethal limits (skull and 597 crossbones, $10^{4}$ sporangia per host Briggs et al. [8]). b. $B d$ and micrograzer dynamics, 598 indicating control of zoospores and sporangia, maintaining sporangia numbers below the 599 lethal limit. c. $B d$ and micrograzer dynamics based on an inferior micrograzer to $T$. 600 pyriformis $\left(0.5 \times I_{\max } ; 2 \times k\right.$ presented in Table 1$)$, indicating the micrograzers inability to prevent host death at $\sim 55$ days (skull and crossbones) but its ability to ultimately reduce $B d$ 602 levels by $100 \mathrm{~d}$.

603 Fig. 6 Exploration of $B d$-micrograzer dynamics (Eq. 1-3), through varying two key 604 micrograzer parameters: the half saturation constant $(k)$ and the maximum ingestion rate 605 ( $\left.I_{\max }\right)$; see Methods for details. To characterise dynamics, we provide the log numbers of 606 zoospores, sporangia, and micrograzers. For each, we present the maximum number reached 607 over the 100 days, the number at 50 days, and the number at 100 days. 
Disease control by micrograzers

610 Table 1 Parameters used to assess $B d$ dynamics (Eq. 1-3). $B d$ parameter estimates are from

611 Briggs et al. [8] who present a wide range of possible values; we have chosen one set of

612 these that provide an illustration of Bd-micrograzer dynamics. Micrograzer data are

613 from our functional response (Fig. 4). Conversion efficiency (e) was estimated as

614 described in the text. The minimum number of micrograzers $(b)$ and micrograzer death

615 rate (d) were derived from personal observations.

\begin{tabular}{|c|c|c|c|c|}
\hline Symbol & Parameter & Estimate & $\begin{array}{l}\text { Range explored } \\
\text { by Briggs et al. } \\
{[7]}\end{array}$ & Dimension \\
\hline$y$ & Rate of zoospores encounter with hosts & $(0.05)$ & $\begin{array}{l}\text { Large range of } \\
\text { values }\end{array}$ & $d^{-1}$ \\
\hline$v$ & Fraction of successful $B d$ spore infections & 0.1 & $0-1$ & dimensionless \\
\hline$\eta$ & $\begin{array}{l}\text { Production rate of zoospores from } \\
\text { sporangium }\end{array}$ & 17.5 & -- & $d^{-1}$ \\
\hline$\sigma$ & Sporangia loss rate & 0.2 & $0.1-0.3$ & $d^{-1}$ \\
\hline$\mu$ & Spore death rate & $0.1(1)$ & $0.02-1$ & $\mathrm{t}^{-1}$ \\
\hline$E$ & Conversion efficiency & $5 \times 10^{-4}$ & & dimensionless \\
\hline$I_{\max }$ & Maximum ingestion rate & 1630 & & $\mathrm{~S} \mathrm{~d}^{-1}$ \\
\hline$K$ & Half saturation constant & $5.75 \times 10^{4}$ & & $\mathrm{~S} \mathrm{ml}^{-1}$ \\
\hline$d$ & Micrograzer death rate & 0.01 & & $\mathrm{t}^{-1}$ \\
\hline$b$ & Minimum number of micrograzers & 1 & & $\mathrm{ml}^{-1}$ \\
\hline
\end{tabular}


bioRxiv preprint doi: https://doi.org/10.1101/2020.02.03.931857; this version posted August 10, 2020. The copyright holder for this preprint (which was not certified by peer review) is the author/funder. All rights reserved. No reuse allowed without permission.

Disease control by micrograzers

Fig. 1

621

622

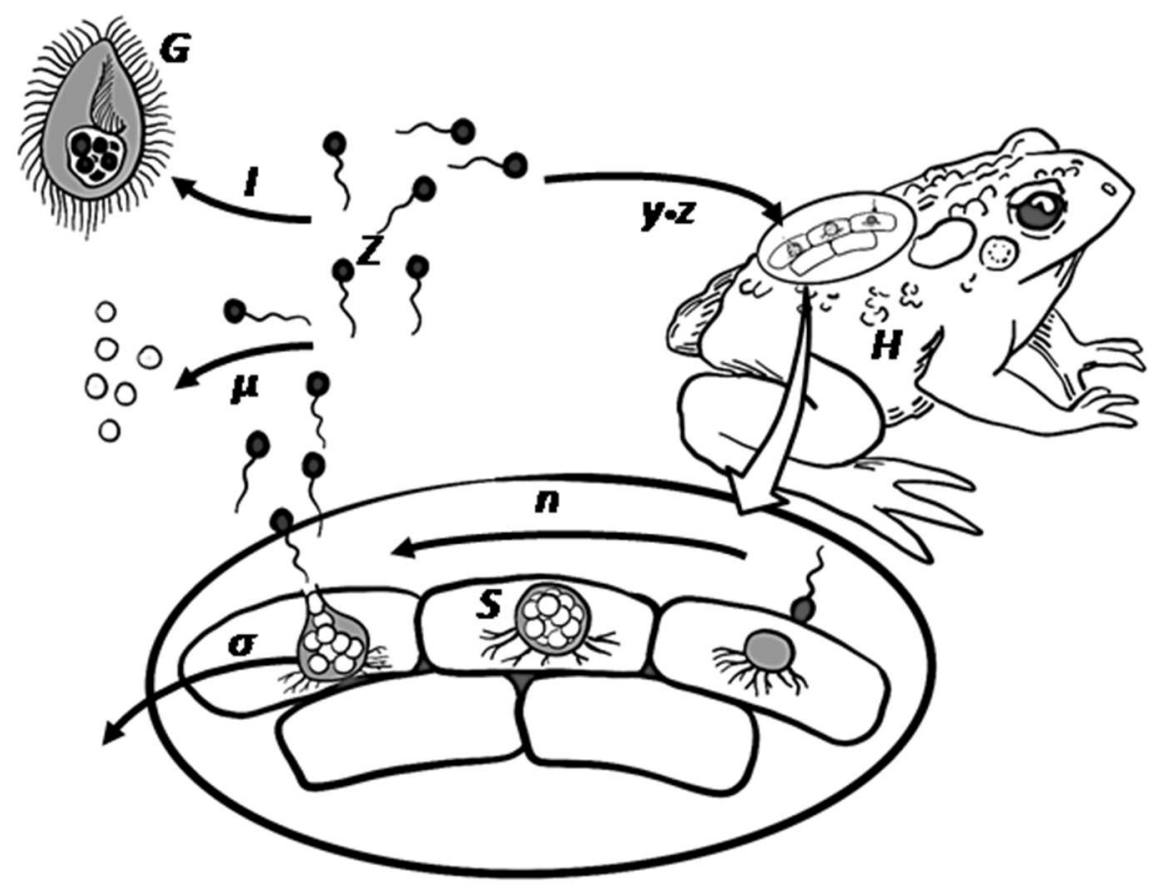


Disease control by micrograzers

Fig. 2

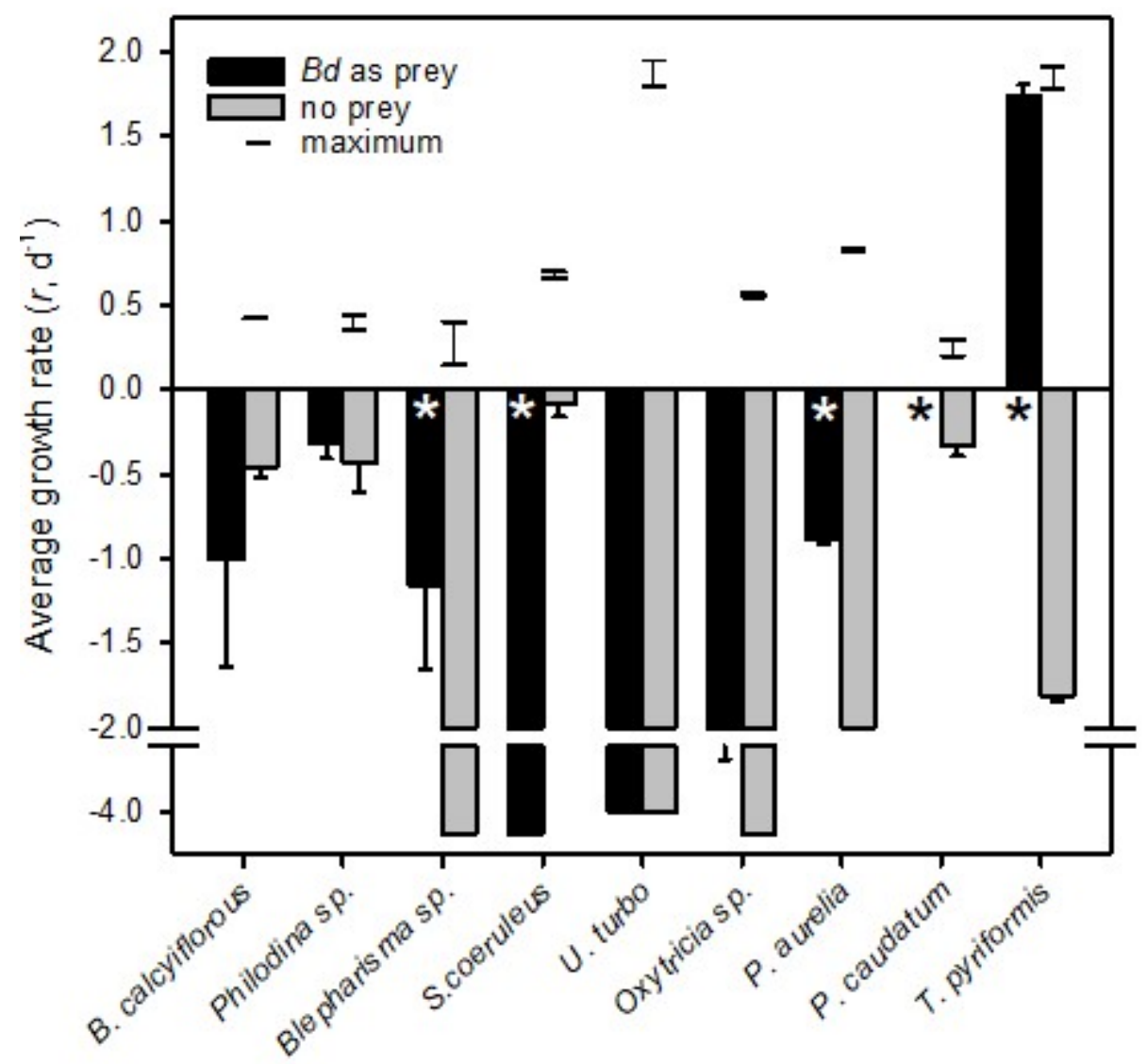


Disease control by micrograzers

Fig. 3
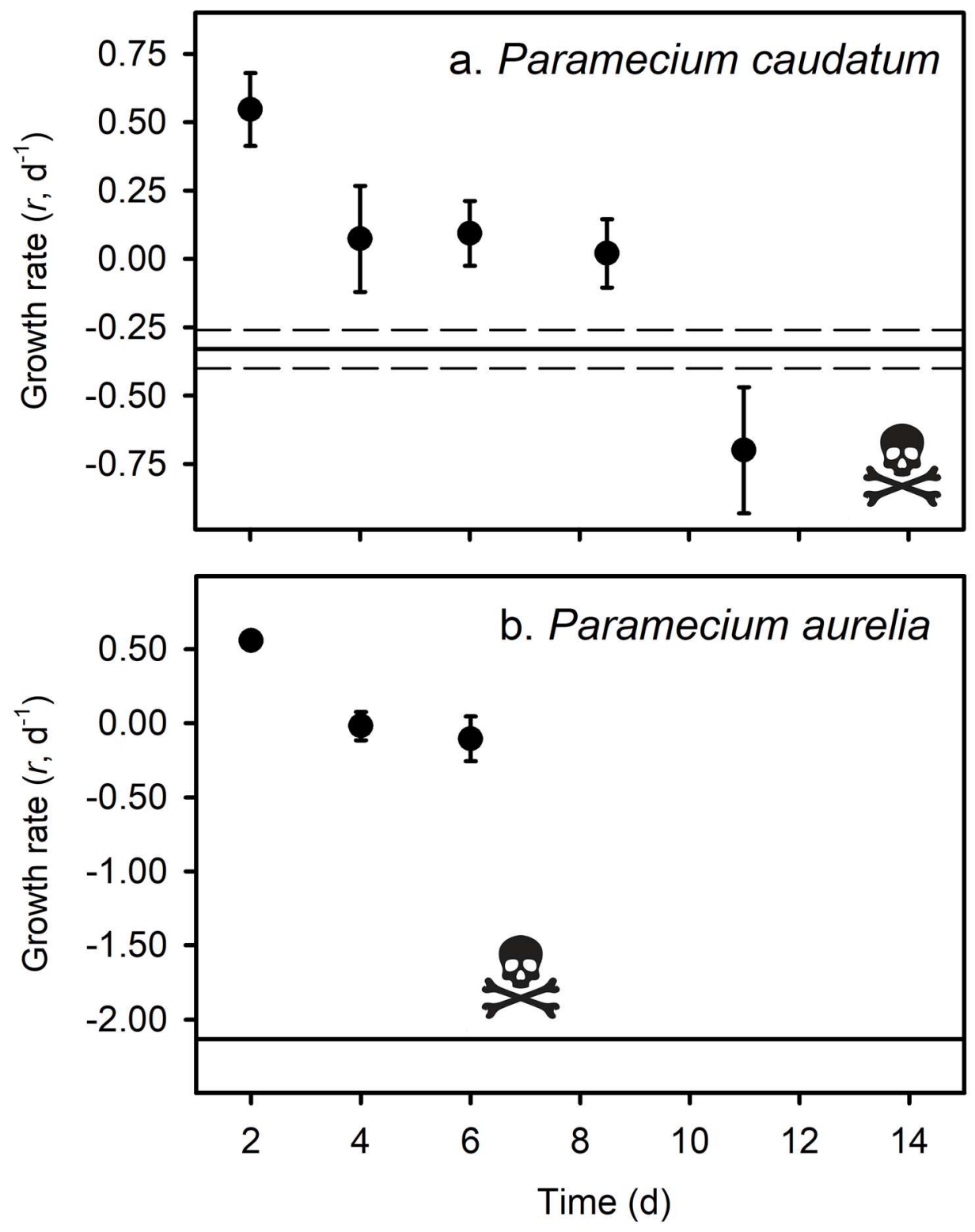
bioRxiv preprint doi: https://doi.org/10.1101/2020.02.03.931857; this version posted August 10, 2020. The copyright holder for this preprint (which was not certified by peer review) is the author/funder. All rights reserved. No reuse allowed without permission.

Disease control by micrograzers

Fig. 4

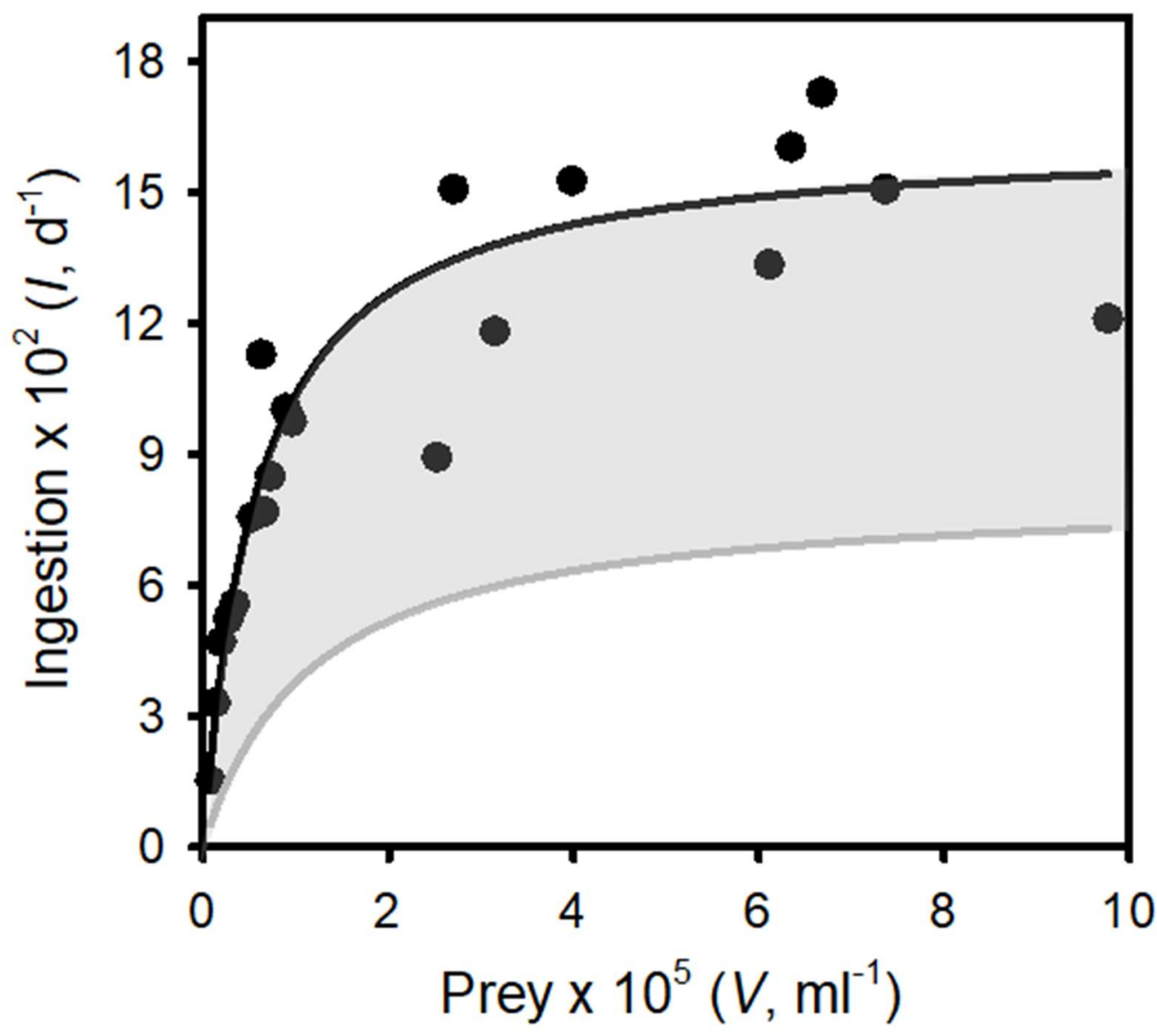


bioRxiv preprint doi: https://doi.org/10.1101/2020.02.03.931857; this version posted August 10, 2020. The copyright holder for this preprint (which was not certified by peer review) is the author/funder. All rights reserved. No reuse allowed without permission.

Disease control by micrograzers

Fig. 5
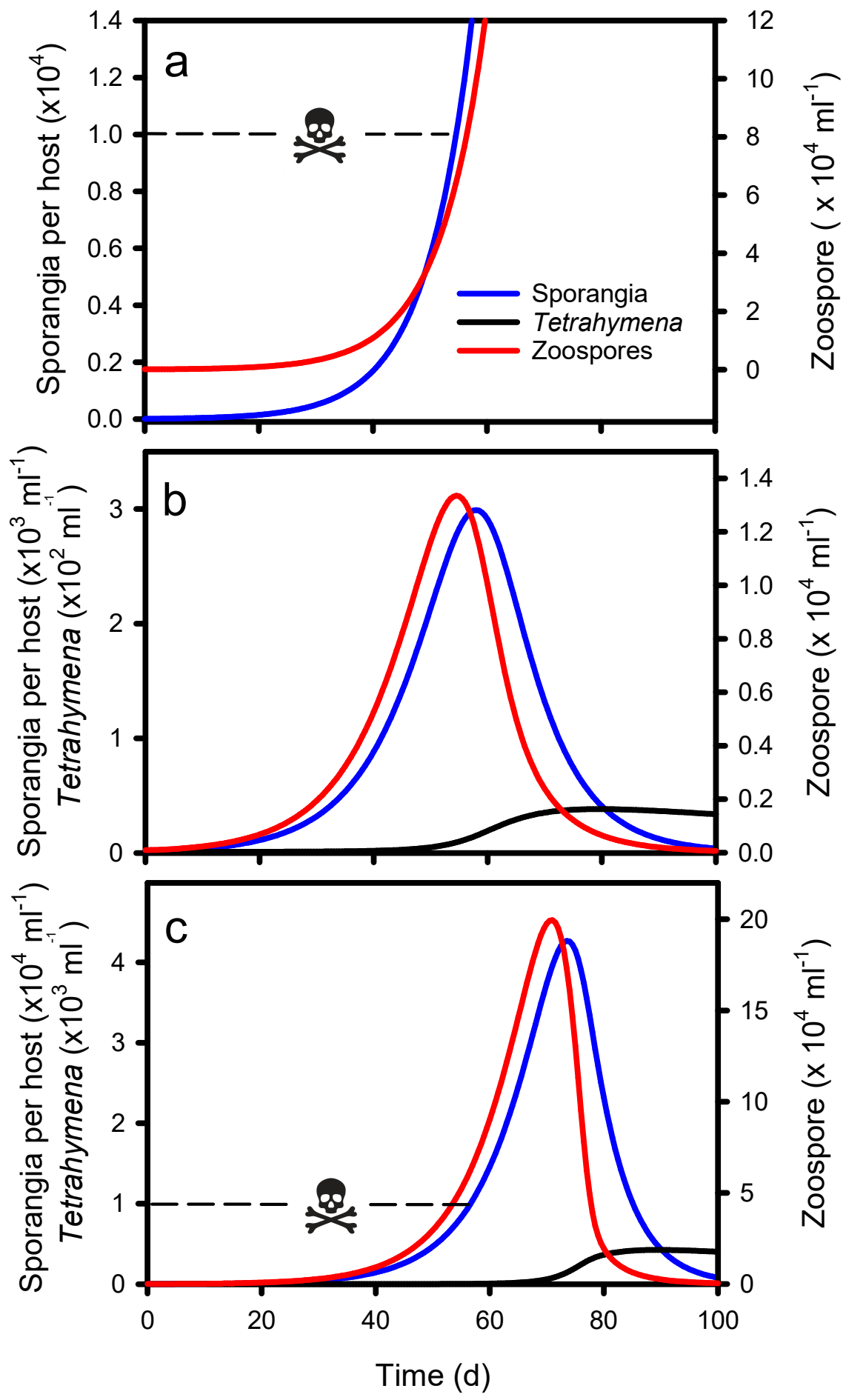
bioRxiv preprint doi: https://doi.org/10.1101/2020.02.03.931857; this version posted August 10, 2020. The copyright holder for this preprint (which was not certified by peer review) is the author/funder. All rights reserved. No reuse allowed without permission.

\section{Disease control by micrograzers}

Fig. 6

631

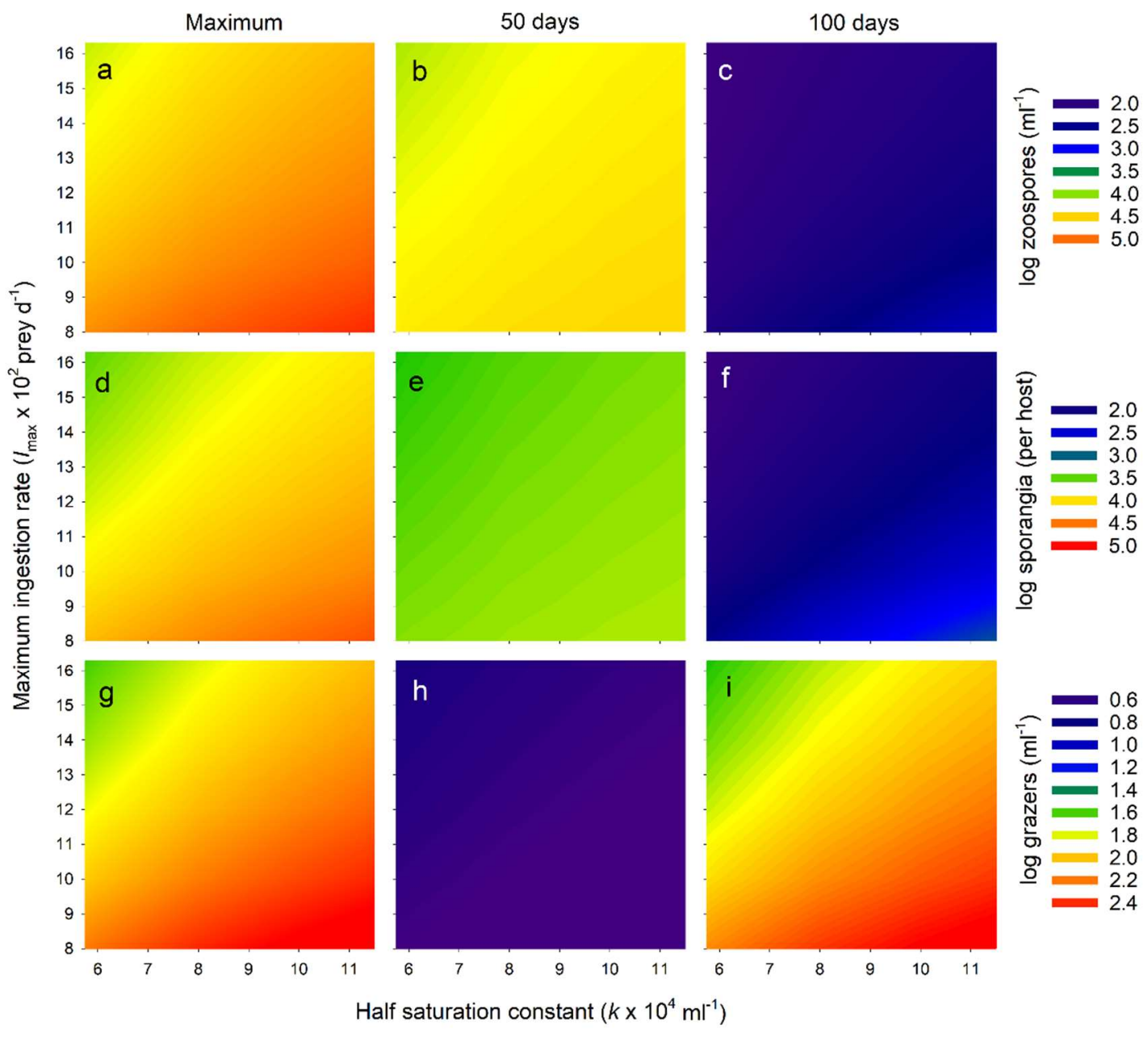

